University of South Carolina

Scholar Commons

1983

\title{
Prediction of the Current Density at an Electrode at Which Multiple Electrode Reactions Occur under Potentiostatic Control
}

\author{
Ralph E. White \\ University of South Carolina - Columbia, white@cec.sc.edu \\ S. E. Lorimer \\ Texas A \& M University - College Station \\ R. Darby \\ Texas A \& M University - College Station
}

Follow this and additional works at: https://scholarcommons.sc.edu/eche_facpub

Part of the Chemical Engineering Commons

\section{Publication Info}

Journal of the Electrochemical Society, 1983, pages 1123-1126.

(c) The Electrochemical Society, Inc. 1983. All rights reserved. Except as provided under U.S. copyright law, this work may not be reproduced, resold, distributed, or modified without the express permission of The Electrochemical Society (ECS). The archival version of this work was published in Journal of the

Electrochemical Society.

http://www.electrochem.org/

DOI: $10.1149 / 1.2119900$

Publisher's Version: http://dx.doi.org/10.1149/1.2119900

This Article is brought to you by the Chemical Engineering, Department of at Scholar Commons. It has been accepted for inclusion in Faculty Publications by an authorized administrator of Scholar Commons. For more information, please contact digres@mailbox.sc.edu. 
at $303.15 \mathrm{~K}(15)$, the corresponding values are 2.76 for $\mathrm{R}=\mathrm{n}-\mathrm{Bu}$ and 2.51 for $\mathrm{R}=\mathrm{n}-\mathrm{Am}$. Both $(i-\mathrm{Am}){ }_{4} \mathrm{NI}$ and $(\mathrm{n}-\mathrm{Am})_{4} \mathrm{NI}$ are regarded as dissociated in DMSO at $298.15 \mathrm{~K}$ (2). For sulfolane, no data are available, but because of the high dielectric constant, high temperature of measurement, and behavior of similar $\mathrm{R}_{4} \mathrm{~N}^{+}$salts (17), we assume that they are both completely dissociated.

Manuscript submitted April 12, 1982; revised manuscript received ca. Aug. 6, 1982.

Any discussion of this paper will appear in a Discussion Section to be published in the December 1983 Journal. All discussions for the December 1983 Discussion Section should be submitted by Aug. 1, 1983.

\section{REFERENCES}

1. M. Spiro, "Physical Chemistry of Organic Solvent Systems," A, K. Covington and T. Dickinson, Editors, p. 636, Plenum Press, New York (1973).

2. J. N. Butler, J. Electroanal. Chem., 14, 89 (1967)

3. N. N. Lichtin and J. F. Reardon, J. Phys. Chem., 84, 2398 (1980)

4. N. N. Lichtin and J. F. Reardon, ibid., 84, 2946 (1980).

5. N. N. Lichtin and J. F. Reardon, ibid., 85, 1590 (1981)

6. N. N. Lichtin and M. J. Vignale, J. Am. Chem. Soc.,
79, 579 (1957)

7. N. N. Lichtin and H. Glazer, ibid., 73, 5537 (1951).

8. T. Shedlovsky, J. Franklin Inst., 225, 739 (1938).

9. D. F. Burow, in "Chemistry of Nonaqueous Solvents," Vol. III, J. Lagowski, Editor, p. 305, Academic Press, New York (1970).

10. R. A. Robinson and R. H. Stokes, "Electrolyte Solutions," p. 396, Butterworths, London, England (1959).

11. M. Spiro, "Physical Chemistry of Organic Solvent Systems" A. K Covington and T. Dickinson, Editors, pp. 261 and 637, Plenum Press, New York (1973)

12. R. L. Kay, in "Water, A Comprehensive Treatise," Vol. III, F. Frank, Editor, Chap. 4, Plenum Press, New York (1973)

13. R. A. Robinson and R. H. Stokes, "Electrolyte Solutions," p. 125, Butterworths, London, England (1959).

14. R. Fernandez-Prini, "Physical Chemistry of Organic Solvent Systems," A. K. Covington and T. Dickinson, Editors, p. 588, Plenum Press, New York (1973).

15. M. Spiro, in "Physical Chemistry of Organic Solvent Systems," A. K. Covington and T. Dickinson Editors, p. 679, Plenum Press, New York (1973)

16. "Physical Chemistry of Organic Solvent Systems," A. K. Covington and T. Dickinson, Editors, p. 5 Plenum Press, New York (1973).

\title{
Prediction of the Current Density at an Electrode at Which Multiple Electrode Reactions Occur under Potentiostatic Control
}

\author{
R. E. White, * S. E. Lorimer, * and R. Darby
}

Chemical Engineering Department, Texas A\&M University, College Station, Texas 77843

It is often desirable to be able to predict the total current density at an electrode when multiple electrochemical reactions occur there under potentiostatic control. It is also sometimes desirable to include the effect of ionic migration within the diffusion layer upon the predicted total (1) and partial current densities (2). A prócedure for doing this can be illustrated by considering the rotating disk electrode (RDE) system and the associated potential distribution near the RDE as shown in Fig. 1 and 2. For simplicity, it is assumed that the concentration of species $i$ in the solution $\left(c_{i}\right)$ and the potential of the solution $(\Phi)$ depend only on the normal coordinate $y$ as shown in Fig. 1. This assumption is reasonable for well-supported solutions and small radius disks. Also, it is assumed that no potential drop exists between the reference electrode within its own compartment and the tip of the Luggin capillary tube.

The procedure consists of writing the Butler-Volmer equation for any general electrochemical reaction $j$ in a particular way, including the effect of ionic migration in the flux expression for species $i$, and writing the boundary conditions for the concentration of species $i$ and the potential in the solution in a specific manner.

\section{Butler-Volmer Equation}

The Butler-Volmer equation for electrochemical reaction $j$ can be written as follows

$$
i_{\mathrm{j}}=i_{\mathrm{oj}, \mathrm{o}}\left[\exp \left(\frac{\alpha_{\mathrm{aj}} \mathbf{F}}{R T} \eta_{\mathrm{sj}}\right)-\exp \left(\frac{-\alpha_{\mathrm{cj}} \mathbf{F}}{R T} \eta_{\mathrm{sj}}\right)\right]
$$

where

$$
\eta_{\mathrm{sj}}=V-\Phi_{\mathrm{o}}-U_{\mathrm{j}, \mathrm{o}}
$$

- Electrochemical Society Active Member.

Key words: interfaces, mass transport, kinetics.

$$
\begin{gathered}
U_{\mathrm{j}, \mathrm{o}}=U_{\mathrm{j}}^{\theta}-\frac{R T}{n_{\mathrm{j}} \mathbf{F}} \sum_{i} s_{i \mathrm{j}} \ln \left(\frac{c_{\mathrm{i}, \mathrm{o}}}{\rho_{0}}\right) \\
-U^{\theta} \mathrm{RE} \\
+\frac{R T}{n_{\mathrm{RE}} \mathbf{F}} \sum_{i} s_{\mathrm{i}, \mathrm{RE}} \ln \left(\frac{c_{\mathrm{i}, \mathrm{RE}}}{\rho_{0}}\right) \\
i_{\mathrm{oj}_{\mathrm{j}, 0}}=i_{\mathrm{oj}, \mathrm{ref}} \pi\left(\frac{c_{i, 0}}{c_{\mathrm{i}, \mathrm{ref}}}\right)^{\gamma_{1 \mathrm{j}}}
\end{gathered}
$$

and

$$
i_{\text {oj,ref }}=i_{\text {oj,data }} \pi\left(\frac{c_{i, \text { ref }}}{c_{\mathrm{i}, \text { data }}}\right)^{\gamma_{1 j}}
$$

As shown in Eq. [1], anodic and cathodic current densities are defined here to be positive and negative, respectively. Also, $s_{i j}$ is pasitive for an anodic reactant and negative for a cathodic reactant. As shown by Eq. $[2]$, the current density $i_{j}$ depends upon the difference between the potential of the electrode $(V)$ and the potential in the solution adjacent to the electrode surface $\left(\Phi_{0}\right)$ relative to the open-circuit potential for reaction $j\left(U_{j, 0}\right)$ evaluated at the surface concentrations of species $i\left(c_{i, 0}\right)$. The values of the potentials $V, \Phi, U_{j}^{\theta}$, and $U^{\theta} \mathrm{RE}$ are all relative to the standard hydrogen reference electrode potential which is defined to be zero for convenience. Thus, if the reference electrode used in the experiment is a standard hydrogen reference electrode, $U_{\mathrm{j}, \mathrm{o}}$ is simply the Nernst equation (1) evaluated at $c_{i, 0}$. Note that $i_{j}$ depends on $c_{i, 0}$ through both $U_{j, 0}$ and the concentration dependence of the exchange current density as given by Eq. [4], which shows that the exchange current density of reaction $j$ evaluated at the surface concentrations $\left(i_{\text {oj,o }}\right)$ can be written in terms of reference concentrations $\left(c_{i, \text { ref }}\right)$. Also note that Eq. [5] can be used to determine a value for $i_{\text {oj,ref }}$ assuming values are known for $i_{\text {oj,data, }}, c_{i, \text { data }}$ and $\gamma_{\mathrm{ij} j}$. The open-circuit potential $U_{j, 0}$ 


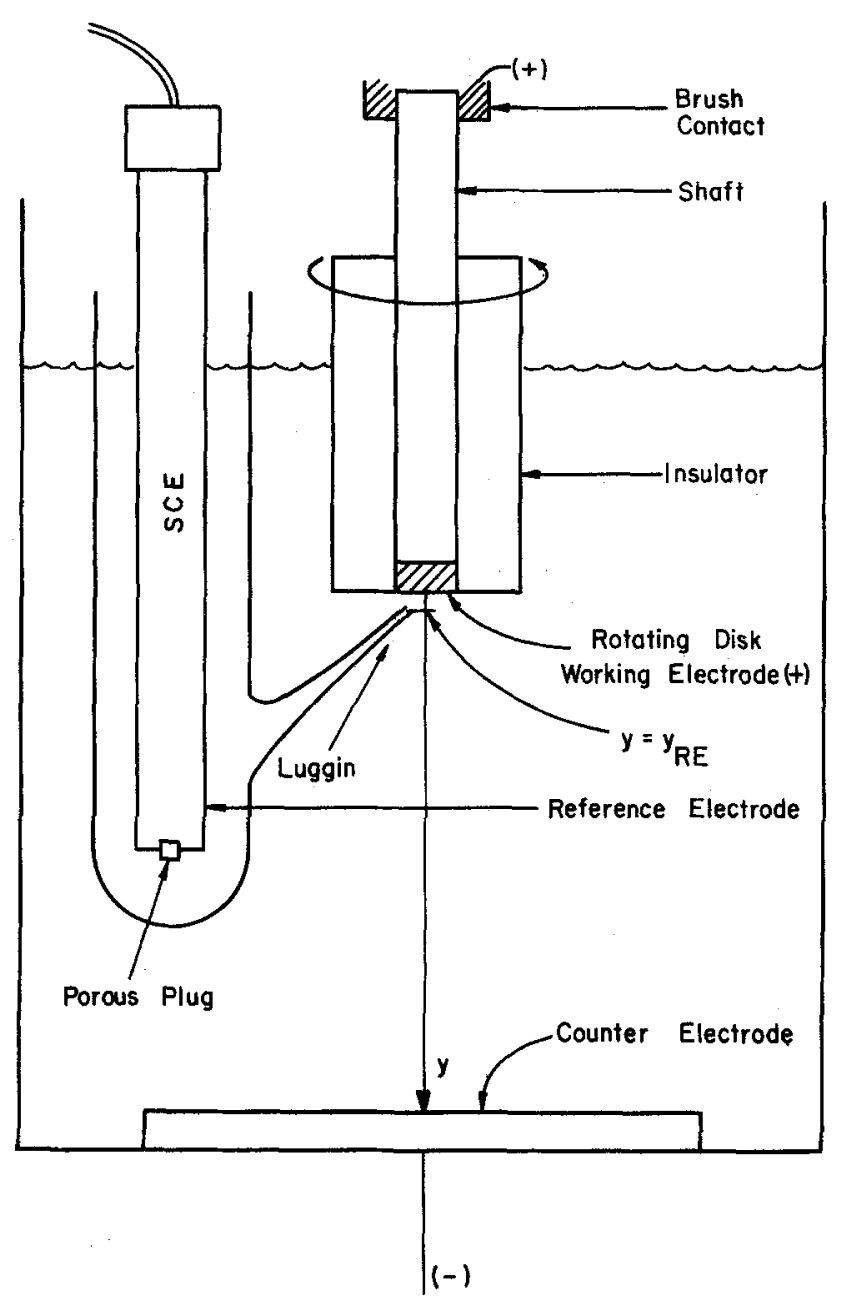

Fig. 1. Schematic of a rotating disk electrode system

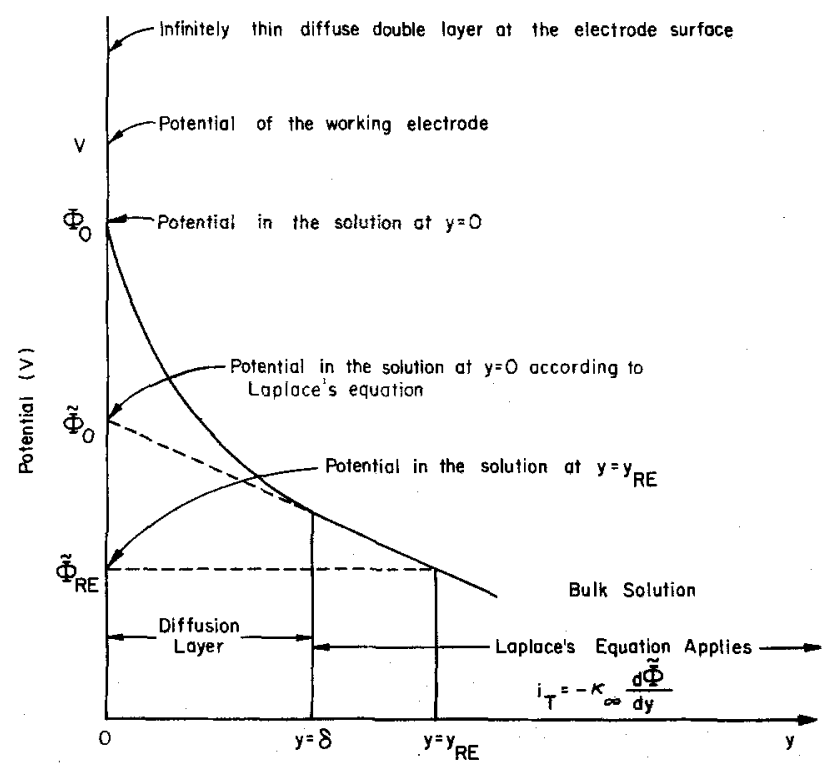

Fig. 2. Schematic of the solution potential profile near an electrode being operated anodically.

can be written in terms of the reference concentrations by adding and subtracting the following term to Eq. [3]

The result is

$$
\frac{R T}{n_{\mathrm{j}} \mathbf{F}} \sum_{i} s_{\mathrm{ij}} \ln \left(\frac{c_{\mathrm{i}, \mathrm{ref}}}{\rho_{\mathrm{o}}}\right)
$$

$$
U_{\mathrm{j}, \mathrm{o}}=U_{\mathrm{j}, \mathrm{ref}}-\frac{R T}{n_{\mathrm{j}} \mathbf{F}} \sum_{i} s_{\mathrm{ij}} \ln \left(\frac{c_{\mathrm{i}, \mathrm{o}}}{c_{\mathrm{i}, \mathrm{ref}}}\right)
$$

$$
\begin{aligned}
& \text { where } \\
& \begin{aligned}
U_{\mathrm{j}, \mathrm{ref}}=U_{\mathrm{j}}^{\theta} & -\frac{R T}{n_{\mathrm{j}} \mathrm{F}} \sum_{i} s_{\mathrm{ij}} \ln \left(\frac{c_{\mathrm{i}, \mathrm{ref}}}{\rho_{0}}\right) \\
& -U^{\theta_{\mathrm{RE}}}+\frac{R T}{n_{\mathrm{RE}} \mathbf{F}} \sum_{i} s_{\mathrm{i}, R \mathrm{E}} \ln \left(\frac{c_{\mathrm{i}_{\mathrm{R}} \mathrm{E}}}{\rho_{\mathrm{o}}}\right)
\end{aligned}
\end{aligned}
$$

Also, the potential difference $V-\Phi_{0}$ in Eq. [2] can be written in terms of the applied or set potential difference $V-\widetilde{\Phi}_{R E}$ as follows

$$
V-\Phi_{0}=V-\tilde{\Phi}_{\mathrm{RE}}-\left(\Phi_{0}-\tilde{\Phi}_{\mathrm{RE}}\right)
$$

where $\tilde{\Phi}_{\mathrm{RE}}$ is the potential in the solution at $\boldsymbol{y}=\boldsymbol{y}_{\mathrm{RE}}$ (see Fig. 1 and 2).

Now, Eq. [2], [4], [7], and [9] can be used to rewrite Eq. [1] in the desired form

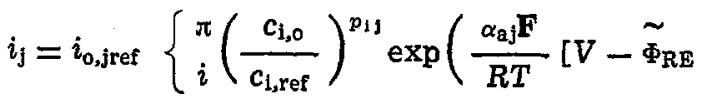

$$
\begin{aligned}
& \left.\left.-\left(\Phi_{0}-\tilde{\Phi}_{\mathrm{RE}}\right)-U_{j, \mathrm{ref}}\right]\right)-{ }_{i}^{\pi}\left(\frac{c_{\mathrm{i}, \mathrm{o}}}{c_{\mathrm{i}, \mathrm{ref}}}\right)^{q_{1 /}} \\
& \left.\exp \left(\frac{-\alpha_{\mathrm{cj}} \mathbf{F}}{R T}\left[V-\tilde{\Phi}_{\mathrm{RE}}-\left(\Phi_{\mathrm{o}}-\tilde{\Phi}_{\mathrm{RE}}\right)-U_{\mathrm{j}, \mathrm{ref}}\right]\right)\right\}
\end{aligned}
$$

where

and

$$
p_{i j}=\gamma_{i j}+\frac{\alpha_{a j} s_{i j}}{n_{j}}
$$

$$
q_{i j}=\gamma_{i j}-\frac{\alpha_{c j} s_{i j}}{n_{j}}
$$

It is useful at this point to compare the potential differences in the arguments of the exponentials in Eq. [10]

$$
V-\tilde{\Phi}_{\mathrm{RE}}-\left(\Phi_{0}-\tilde{\Phi}_{\mathrm{RE}}\right)-U_{\mathrm{j}, \mathrm{ref}}
$$

to those used commonly by others (3) in similar expressions. Typically, the potential differences used by others (3) are

$$
E_{\text {appl }}-E_{\text {eq }}-i_{\mathrm{T}} A R_{\mathrm{s}}
$$

where $E_{\text {appl }}$ is defined to be the potential difference between the working electrode and a reference electrode placed in the bulk solution with current being passed in the cell, $E_{\mathrm{eq}}$ is that same potential difference when no current is being passed, and $i_{\mathrm{T}} A R_{\mathrm{s}}$ is the ohmic potential drop in the solution between the working and reference electrodes. It should be pointed out that the potential in the solution at $y_{\mathrm{RE}}$ depends upon the current being passed; it is not a constant as is often assumed (3). The potential differences given by Eq. [13] and [14] are not the same because, even though

$$
E_{\mathrm{appl}}=V-\tilde{\Phi}_{\mathbf{R E}}
$$

and for a single electrode reaction

$$
E_{\text {eq }}=U_{\mathrm{j}, \mathrm{ref}}
$$

the ohmic drop through the diffusion layer is different. That is

$$
i_{\mathrm{T}} A R_{\mathrm{S}} \neq \Phi_{\mathrm{o}}-\tilde{\Phi}_{\mathrm{RE}}
$$

The ohmic potential drops are not the same because the specific conductivity $\left(\kappa_{\infty}\right)$ of the electrolyte is not constant through the diffusion layer as is often assumed by others (3). That is, if it is assumed that both $i_{\mathrm{T}}$ and $\kappa_{\infty}$ are constants through the diffusion layer, then Laplace's equation 


$$
i_{\mathrm{T}}=-\kappa_{\infty} \frac{\tilde{d \Phi}}{d y}
$$

can be integrated to give

$$
\frac{i_{\mathrm{T}} y_{\mathrm{RE}}}{\kappa_{\infty}}=\tilde{\Phi}_{0}-\Phi_{\mathrm{RE}}
$$

which can be rewritten in terms of the solution resistance $\left(R_{\mathrm{S}}\right)$ by using the following equation (3)

$$
R_{\mathrm{s}}=\frac{y_{\mathrm{RE}}}{\kappa_{\mathrm{s}} A}
$$

Thus, by using Eq. [20], Eq. [19] becomes

$$
i_{\mathrm{T}} A R_{\mathrm{s}}=\tilde{\Phi}_{\mathrm{o}}-\tilde{\Phi}_{\mathrm{RE}}
$$

Comparison of Eq. [17] and [21] shows that $\Phi_{0} \neq \tilde{\Phi}_{0}$ as illustrated schematically in Fig. 2. Typically, it is assumed, however, that $\Phi_{0}=\tilde{\Phi}_{0}$, which is often not true $(2,4)$.

It should be noted that both $E_{\text {appl }}$ and $V-\widetilde{\Phi}_{R E}$ depend upon the type of reference electrode used, since they both represent the same physical quantity. (It can

be seen that $V-\widetilde{\Phi}_{R E}$ must depend upon the type of reference electrode used in the experiment since at equilibrium

$$
V-\widetilde{\Phi}_{\mathrm{RE}}=U_{\mathrm{j}, \mathrm{ref}}
$$

and $U_{\mathrm{j}, \text { ref }}$ depends upon the type of reference electrode used. (Note that the potential difference $\Phi_{0}-\tilde{\Phi}_{R E}$ is equal to zero at equilibrium.) In addition, $E_{\text {eq }}$ and $U_{j, \text { ref }}$ depend in the same manner upon the type of reference electrode used (3). Consequently, the difference between $V-\tilde{\Phi}_{R E}$ and $U_{j, \text { ref }}$ is independent of the type of reference electrode used in the experiment, as is $E_{\mathrm{appl}}-E_{\text {eq. }}$.

\section{Governing Equations and Boundary Conditions for $c_{i}$ and $\Phi$}

The governing equation for the concentration of species $i$ at steady-state conditions and no homogeneous reactions is (1)

$$
\frac{d N_{\mathrm{i}}}{d y}=0
$$

where

$$
N_{\mathrm{i}}=-D_{\mathrm{i}} \frac{d c_{\mathrm{i}}}{d y}-z_{\mathrm{i}} \frac{D_{\mathrm{i}} c_{\mathrm{i}} \mathbf{F}}{R T} \frac{d \Phi}{d y}+v c_{\mathrm{i}}
$$

and the governing equation for the potential in the solution is the electroneutrality condition (1)

$$
\Sigma z_{\mathrm{i}} c_{\mathrm{i}}=0
$$

The boundary conditions for a single electrode reaction are as follows

$$
\text { at } y=0 \quad\left\{\begin{array}{c}
\Sigma z_{\mathrm{i}} c_{\mathrm{i}}=0 \\
V=\text { a set constant }(e . g ., 0.2 \mathrm{~V}) \\
\frac{\mathrm{s}_{\mathrm{i} j} i_{\mathrm{j}}}{n_{\mathrm{j}} \mathrm{F}}=-N_{\mathrm{i}}
\end{array}\right.
$$

where $N_{1}$ is given by Eq. [24] with $v=0$ and $i_{j}$ is given by Eq. [10]

$$
\text { at } y=y_{\mathrm{RE}}\left\{\begin{array}{c}
c_{\mathrm{i}}=\mathrm{c}_{\mathrm{i}, \mathrm{ref}} \text { where } \underset{i}{\Sigma z_{\mathrm{i}} c_{\mathrm{i}, \mathrm{ref}}=0} \\
\Phi=\tilde{\Phi}_{\mathrm{RE}}=\text { a set constant } \\
(\text { e.g., } 0.1 \mathrm{~V})
\end{array}\right.
$$

It is important to note that both $V$ and $\widetilde{\Phi}_{\mathrm{RE}}$ must be set such that their difference $\left(V-\tilde{\Phi}_{R E}\right)$ is equal to the value set by the potentiostat.

Once values have been set for the parameters of the system, the solution of Eq. [23] and [25] subject to Eq. [20]-[30] yields values for $c_{\mathrm{i}}(y)$ and $\Phi(y)$. The values of $c_{i}$ and $\Phi$ at $y=0\left(c_{i, 0}\right.$ and $\left.\Phi_{0}\right)$ can then be used together with the kinetic parameters to predict the current density of reaction $j$ according to Eq. [10].

If more than one electrode reaction occurs, Eq. [28] must be changed to

$$
\sum_{j} \frac{s_{i j} \dot{i}_{j}}{n_{j} \mathbf{F}}=-N_{i}
$$

where $i_{\mathrm{j}}$ is given by Eq. [10] with the appropriate kinetic parameters. The total predicted current density $\left(i_{\mathrm{T}}\right)$ can, then, be obtained by solving the equations and summing the current densities due to the individual reactions as follows

$$
i_{\mathrm{T}}=\sum_{j} i_{\mathrm{j}}
$$

It is worth noting that even if the effect of ionic migration is negligible, the procedure presented here is useful because it permits the direct use in the model of the set potential difference between the working electrode and a reference electrode in the bulk solution, and it provides a method of predicting the current densities of the individual reactions when multiple electrode reactions occur.

Finally, it should be mentioned that a less direct method could be used for a single electrode reaction but would be difficult to apply for multiple electrode reactions. The procedure would consist of setting $i_{\mathrm{j}}$ in Eq. [28] and, then, determining $\Phi_{0}$ by solving the transport problem. This value of $\Phi_{0}$ could, then, be used in Eq. [10] to obtain $V-\tilde{\Phi}_{\mathrm{RE}}$ which could be compared to the observed value and a new $i_{\mathrm{j}}$ selected, if necessary. Since this would be an iterative procedure, it would be difficult to implement particularly for multiple electrode reactions, especially if the current densities due to the individual reactions were not equal, as is often the case.

Manuscript submitted Aug. 9, 1982; revised manuscript received Jan. 3, 1983.

Any discussion of this paper will appear in a Discussion Section to be published in the December 1983 JoURNAL. All discussions for the December 1983 Discussion Section should be submitted by Aug. 1, 1983.

\section{LIST OF SYMBOLS}

$A$ area of the electrode, $\mathrm{cm}^{2}$

$c_{i}$ concentration of species $i, \mathrm{~mol} / \mathrm{cm}^{3}$

ciocal surface concentration of species $i, \mathrm{~mol} / \mathrm{cm}^{3}$

$c_{i, \text { data }}$ data concentration of species $i, \mathrm{~mol} / \mathrm{cm}^{3}$

$c_{i, \text { ref }}$ reference concentration of species $i, \mathrm{~mol} / \mathrm{cm}^{3}$

$D_{i}$ diffusion coefficient of species $i, \mathrm{~cm}^{2} / \mathrm{sec}$

$E_{\text {appl }}$ potential of working electrode relative to potential of a reference electrode of a given kind, $\mathrm{V}$

$E_{\text {eq }}$ potential of working electrode relative to potential of a reference electrode of a given kind when no current is passed, $\mathrm{V}$

F Faraday's constant, $96,487 \mathrm{C} / \mathrm{mol}$

$i_{i} \quad$ current density due to reaction $j, \mathrm{~A} / \mathrm{cm}^{2}$

$i_{\text {oj,data }}$ exchange current density at concentrations reported in the literature $\left(c_{\mathrm{i}, \mathrm{data}}\right), \mathrm{A} / \mathrm{cm}^{2}$

$i_{\text {oj,ref }}$ exchange current density at reference concentrations, $\mathrm{A} / \mathrm{cm}^{2}$

$i_{T} \quad$ total current density, $\mathrm{A} / \mathrm{cm}^{2}$

$n_{\mathbf{j}} \quad$ number of electrons transferred in reaction $j$

$p_{i 1} \quad$ anodic reaction order of species $i$ in reaction $j$

$q_{i, j} \quad$ cathodic reaction order of species $i$ in reaction $j$

$q_{\mathrm{i} . \mathrm{i}} \quad$ universal gas constant, $8.3143 \mathrm{~J} / \mathrm{mol} \mathrm{K}$

$R_{\text {s }} \quad$ solution resistance, $\Omega$

$s_{i j} \quad$ stoichiometric coefficient of species $i$ in reaction $j$

$T$ absolute temperature, $\mathrm{K}$

$U_{\mathrm{j}, 0}$ theoretical open-circuit potential for reaction $j$ 
at the surface concentrations of the species $i$ which participate in reaction $j, \mathrm{~V}$

$U_{\mathbf{j}, \text { ref }}$ theoretical open-circuit potential evaluated at reference concentrations, $\mathrm{V}$

$U_{j}{ }^{\theta} \quad$ standard electrode potential for reaction $j, \mathrm{~V}$ potential of the working electrode, $\mathrm{V}$

$\begin{array}{ll}y & \text { normal coordinate, } \mathrm{cm} \\ y_{\mathrm{RE}} & \text { position of the reference electrode, } \mathrm{cm}\end{array}$

$z_{i} \quad$ charge number of species $i$

\section{Greek Symbols}

$\alpha_{a j} \quad$ anodic transfer coefficient for reaction $j$

$\alpha_{c i} \quad$ cathodic transfer coefficient for reaction $j$

$\gamma_{\mathrm{ij}}$ exponent in the composition dependence of the exchange current density

diffusion layer thickness, $\mathrm{cm}$

pure solvent density, $\mathrm{kg} / \mathrm{cm}^{3}$

potential in the solution within the diffusion layer, $\mathrm{V}$

$\tilde{\Phi}$ potential in the bulk solution, $V$

$\Phi_{0}$
$\tilde{\Phi}_{0} \quad$ potential in the solution at $y=0$ obtained by integrating Laplace's equation with constant $i_{\mathrm{T}}$ and $\kappa_{\infty}, \mathrm{V}$

$\widetilde{\Phi}_{\mathrm{RE}}$ potential in the bulk solution at $y_{\mathrm{RE}}, \mathrm{V}$

$\kappa_{\infty} \quad$ bulk solution specific conductivity, $\Omega^{-1} \mathrm{~cm}^{-1}$

Subscripts

o at the electrode surface

$\mathrm{RE} \quad$ reference electrode

ref reference conditions

\section{REFERENCES}

1. J. S. Newman, "Electrochemical Systems," PrenticeHall, Inc., Englewood Cliffs, NJ (1973).

2. R. E. White, J. A. Trainham, J. Newman, and T. W. Chapman, This Journal, 124, 669 (1977).

3. A. J. Bard and L. R. Faulkner, "Electrochemical Methods: Fundamentals and Applications," John Wiley \& Sons, New York (1980)

4. R. E. White, Ph.D. Thesis, University of California, Berkeley (1977). 